\title{
MAPPING OF CORAL REEF ENVIRONMENT IN THE ARABIAN GULF USING MULTISPECTRAL REMOTE SENSING
}

\author{
H. Ben-Romdhane*, P.R. Marpu, H. Ghedira, T.B.M.J. Ouarda \\ Institute Centre for Water and Environment (iWater) \\ Masdar Institute of Science and Technology, PO Box 54224, Abu Dhabi, UAE \\ *hben@masdar.ac.ae
}

WG VIII/9 - Coastal and Ocean Applications

KEY WORDS: Mapping, Coral Reef, Benthic Habitats, DubaiSat-2, Arabian Gulf

\begin{abstract}
:
Coral reefs of the Arabian Gulf are subject to several pressures, thus requiring conservation actions. Well-designed conservation plans involve efficient mapping and monitoring systems. Satellite remote sensing is a cost-effective tool for seafloor mapping at large scales. Multispectral remote sensing of coastal habitats, like those of the Arabian Gulf, presents a special challenge due to their complexity and heterogeneity. The present study evaluates the potential of multispectral sensor DubaiSat-2 in mapping benthic communities of United Arab Emirates. We propose to use a spectral-spatial method that includes multilevel segmentation, nonlinear feature analysis and ensemble learning methods. Support Vector Machine (SVM) is used for comparison of classification performances. Comparative data were derived from the habitat maps published by the Environment Agency-Abu Dhabi. The spectral-spatial method produced $96.41 \%$ mapping accuracy. SVM classification is assessed to be 94.17\% accurate. The adaptation of these methods can help achieving well-designed coastal management plans in the region.
\end{abstract}

\section{INTRODUCTION}

The United Arab Emirates is bordered by the Arabian Gulf. The coasts and islands that flank Abu Dhabi, the UAE's largest emirate host a number of important marine habitats, such as mangroves, seagrass beds and coral reefs (Abed and Hellyer, 2001; Al-Cibahy et al., 2012). Being subject to pressures from urban and industrial encroachment and from climate change, these coastal environments are threatened (Rezai et al., 2004) and, therefore, require efficient mapping and monitoring systems. The complexity and heterogeneity of shallow coastal waters provide a challenging environment for mapping and monitoring using remote sensing imagery (Lesser and Mobley, 2007). Multispectral remote sensing is commonly known as the most cost-effective tools for seafloor description on large spatial and temporal scales (Andréfouët et al., 2008). However, it does not enclose all of the information required to address the issues faced currently. Integrating MS imagery with several processing tools and techniques is a promising option (Yamano, 2013). The proposed approach uses advanced spectral-spatial methods to make the best use of the high resolution offered by DubaiSat-2 over Dalma Island (Latitude: $24.54534^{\circ} \mathrm{N}$, Longitude: $52.30307^{\circ} \mathrm{E}, 42 \mathrm{~km}$ off the coast of Abu Dhabi). This study is one of the first few studies on the utility of DubaiSat-2 images for marine applications and intends to examine the potential of the proposed approach to provide accurate classification of benthic habitats; essential tools for management and sustainable development of marine environments in the Arabian Gulf.

\section{MATERIAL AND METHODS}

\subsection{DubaiSat-2}

DubaiSat-2 is the $2^{\text {nd }}$ earth observation mini satellite of UAE successfully launched in November 2013 in a sun-synchronous orbit of $600 \mathrm{~km}$ altitude. DubaiSat-2 provides high-resolution images. Its sensor has $1 \mathrm{~m}$ panchromatic band and $4 \mathrm{~m}$ multispectral bands: Red (R) $(600-720 \mathrm{~nm})$, Green $(\mathrm{G})(510-580 \mathrm{~nm})$, Blue (B) $(420-510 \mathrm{~nm})$ and Near-InfraRed (NIR) $(760-890 \mathrm{~nm})$. The high spatial resolution advances the potentiality and accuracy of its mapping applications such as the seabottom profiling and the discrimination of marine habitats.

\subsection{Study Site}

The study site captured on June $18^{\text {th }}, 2014$ by DubaiSat- 2 holds important seafloor features such as reefs, seagrass beds, macroalgae and sand flats with spatial arrangement in depths from the intertidal to $15 \sim 30 \mathrm{~m}$. An arrangement that is typical to those found in shallow, nearshore coral reef ecosystems around the world (Walker, 2012), thereby providing a representative coastal area to understand and assess the status of corals and other marine habitats.

\subsection{Proposed Approach}

In order to meet the study's objectives, Level Geo images (radiometrically and geometrically corrected) were processed using a spectral-spatial method that combined different techniques. Objects that grouped pixels with similar spectral and spatial properties were, 
first, extracted using eCognition ${ }^{\circledR}$ through multilevel segmentation (Baatz and Schäpe, 2000). Obtained segments were then assigned to given benthic classes issued from the marine habitat maps published by Environment Agency - Abu Dhabi (EAD) in 2015 (EAD, 2015). This assignment was done according to the analyst's knowledge and expertise to help build comparative data. Furthermore, nonlinear feature reduction method was considered; that is the Kernel-Principal Component Analysis (KPCA) (Schölkopf et al., 1998). KPCA values were attributed to the multi-level objects creating spectral-spatial profiles that were then used for classification using Random Forest (RF) classifier. RF is an advanced nonlinear model for sub-pixel classification (Breiman, 2001). The mapping accuracy of the resulting classification was evaluated using user-, producer- and overall accuracy (Congalton, 1991). Support Vector Machine (SVM) method (Cortes and Vapnik, 1995) was used for comparison of the mapping accuracy with the spectral-spatial method. The differences in classification that results from the two sets of methods were assessed using the McNemar test (Alan, 2002).

\section{RESULTS AND DISCUSSION}

KPCA feature analysis of the MS image of Dalma Island resulted in 20 bands (Figure 1.a). KPCA values that were attributed to the segmentation objects are shown in Figure 1.b. The resulting spectralspatial profiles led to an enhanced spectral separability (Figure 1.c). The classification map obtained after the application of the spectralspatial method is represented below (Figure 2). The overall accuracy was calculated to be $96.41 \%$. The producer and user accuracies are tabulated below (Table I). The class that contained reef rubble and macroalgae presented the lowest producer and user accuracies; $47.57 \%$ and $54.07 \%$, respectively. This could be due to the spectral complexity of this class. Fringing reef class showed more accurate classification but lower than that obtained from underlying bottoms. Misclassifications could be attributed to different conditions at the acquisition times of the image and comparative data. SVM produced 94.17\% overall accuracy. Results from the McNemar test (Table 2) indicated a significant difference between the classification methods in favor of the spectral-spatial method. In Table 2 units are number of pixels. Classification results from the spectral-spatial method (Spespa) are proven more accurate since 41,929 pixels were correctly classified vs. 40,507 pixels from the SVM.

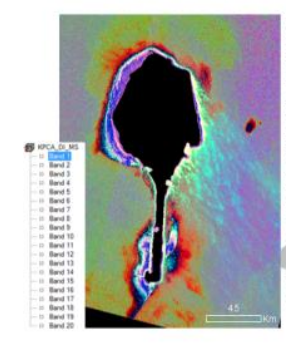

(a)

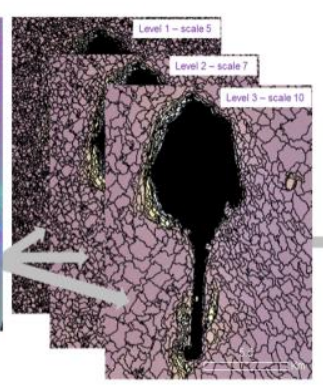

(b)

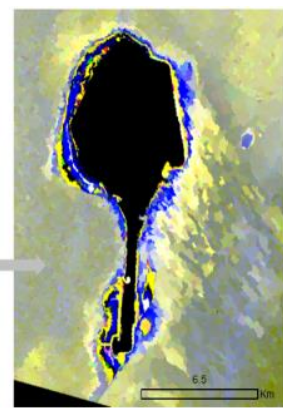

(c)
Figure 1. Results from the processing steps of the spectral-spatial method

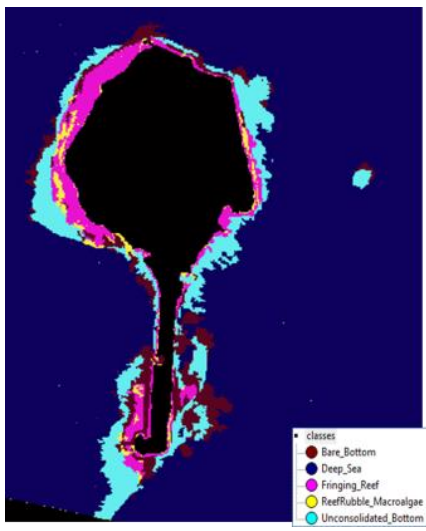

Figure 2. DubaiSat-2 classification map of Dalma Island

\begin{tabular}{|l|c|c|}
\hline & \multicolumn{2}{|c|}{ Accuracies } \\
\hline Class & Producer & User \\
\hline Deep sea & 99.87 & 99.30 \\
Fringing reef & 76.12 & 62.04 \\
Bare bottom & 67.15 & 87.29 \\
Reef rubble and macroalgae & 47.57 & 54.07 \\
Unconsolidated bottom & 89.52 & 95.28 \\
\hline
\end{tabular}

Table 1. Margin settings for A4 size paper

\begin{tabular}{|c|c|c|c|c|}
\cline { 3 - 5 } \multicolumn{2}{c|}{} & \multicolumn{3}{c|}{ Spe-spa } \\
\cline { 3 - 5 } \multicolumn{2}{c|}{} & + & - & $\begin{array}{c}\text { Total } \\
\text { pixels }\end{array}$ \\
\hline \multirow{4}{*}{ SVM } & + & 40083 & 424 & $\begin{array}{c}40507 \\
(93.25 \%)\end{array}$ \\
\cline { 2 - 5 } & - & 1846 & 1088 & $\begin{array}{c}2934 \\
(6.75 \%)\end{array}$ \\
\cline { 2 - 5 } & $\begin{array}{c}\text { Total } \\
\text { pixels }\end{array}$ & $\begin{array}{c}41929 \\
(96.52 \%)\end{array}$ & $\begin{array}{c}1512 \\
(3.48 \%)\end{array}$ & 43441 \\
\hline
\end{tabular}

Table 2. Contingency table for comparison of classification schemes. (+) indicates the number of well-classified pixels and (-) indicates the number of misclassified pixels.

\section{CONCLUSION}

Images from DubaiSat-2 were processed and analyzed using multiple techniques in order to assess its potential in characterizing and mapping the coral reefs and benthic habitats in the waters flanking Abu Dhabi. The generated classification map showed high overall accuracy and alignment with maps published by EAD. These results confirm that DubaiSat-2 has the capability and potential to discern among marine habitat communities despite the complexity and dynamism of the study area. The achievement of the adaptation of these methods to the region of concern also results in an important step towards well designed local and regional coastal management plans and strategies. 


\section{ACKNOWLEDGMENT}

We would like to express our gratitude to Mohammed Bin Rashid Space Centre (MBRSC) for the provision of data.

\section{REFERENCES}

Abed, I., Hellyer, P., 2001. United Arab Emirates: a new perspective. Trident Press Ltd.

Al-Cibahy, A.S., Al-Khalifa, K., Böer, B., Samimi-Namin, K., 2012. Conservation of marine ecosystems with a special view to coral reefs in the gulf, Coral Reefs of the Gulf. Springer, pp. 337-348.

Alan, A., 2002. Categorical data analysis. A John Wiley and Sons, Inc. Publication, Hoboken, New Jersey, USA.

Andréfouët, S., Costello, M.J., Rast, M., Sathyendranath, S., 2008. Earth observations for marine and coastal biodiversity and ecosystems. Remote Sensing of Environment 112, 3297-3299.

Baatz, M., Schäpe, A., 2000. Multiresolution segmentation: an optimization approach for high quality multi-scale image segmentation. Herbert Wichmann Verlag: Berlin, Germany, pp. 1223.

Breiman, L., 2001. Random forests. Machine learning 45, 5-32.
Congalton, R.G., 1991. A review of assessing the accuracy of classifications of remotely sensed data. Remote sensing of environment 37, 35-46.

Cortes, C., Vapnik, V., 1995. Support vector machine. Machine learning 20, 273-297.

EAD, Environment Agency- Abu Dhabi-. 2015. Enviroportal (Environment Agency - Abu Dhabi Geoportal).

Lesser, M., Mobley, C., 2007. Bathymetry, water optical properties, and benthic classification of coral reefs using hyperspectral remote sensing imagery. Coral Reefs 26, 819-829.

Rezai, H., Wilson, S., Claereboudt, M., Riegl, B., 2004. Coral reef status in the ROPME sea area: Arabian/Persian Gulf, Gulf of Oman and Arabian Sea. Status of coral reefs of the world 1, 155-170.

Schölkopf, B., Smola, A., Müller, K.-R., 1998. Nonlinear component analysis as a kernel eigenvalue problem. Neural computation 10, 1299-1319.

Walker, B.K., 2012. Spatial analyses of benthic habitats to define coral reef ecosystem regions and potential biogeographic boundaries along a latitudinal gradient. PloS one 7, e30466.

Yamano, H., 2013. Multispectral applications, Coral Reef Remote Sensing. Springer, pp. 51-78. 